\title{
Do que falamos quando falamos de música? Relatos de uma oficina de escuta
}

Jorge de La Barre (ed.)

Universidade Federal Fluminense, Niterói, Brasil

e-mail: jorgelabarre@id.uff.br

Evelyn Christine da Silva Matos (ed.)

Universidade Federal Fluminense, Niterói, Brasil

eudapinheiro67@gmail.com

Recepción: marzo 2020.

Aceptación: junio 2020.

\section{Resumo}

Este artigo coletivo é um relato de experiência da "Oficina MP3" realizada em sala de aula durante o primeiro semestre de 2018 no curso de Sociologia da música (graduação). A ideia era que cada aluno trouxesse e apresentasse à turma uma música da sua escolha. A diversidade de escolhas musicais, sugerida pelos relatos de alunos, foi organizada seguindo duas linhas temáticas bastante exploradas em sociologia da música: música e representação, e música e significado.

Palavras-chave: circulação, fronteiras simbólicas, música, representação, significado

\section{What Do We Talk About When We Talk About Music? Reports on a Listening Workshop}

\begin{abstract}
This collective paper is a report of an "MP3 Workshop" experience held in the classroom during the first semester of 2018 in the Sociology of Music graduate course taught by Professor Jorge de La Barre (PPGS-UFF). The idea was for each student to bring and present to the class a song of their choice. The diversity of musical choices, suggested by the students' reports,
\end{abstract}


has been organized according to two thematic lines usually explored in music sociology: music and representation, and music and meaning.

Keywords: Circulation, symbolic boundaries, music, representation, meaning

\section{¿De qué hablamos cuando hablamos de música? Informes de un taller de audición}

\section{Resumen}

Este artículo colectivo informa la experiencia del taller "Oficina de MP3" realizado en el aula durante el primer semestre de 2018 en el curso de Sociología de la Música (grado), impartido por el profesor Jorge de La Barre (PPGS-UFF). La idea fue que cada alumno trajera y presentara en la clase una canción de su elección. La diversidad de opciones musicales, sugerida por los informes de los estudiantes, se organizó de acuerdo con dos líneas temáticas exploradas en sociología musical: música y representación, y música y significado.

Palabras clave: circulación, fronteras simbólicas, música, representación, significado

\section{Introdução}

Jorge de La Barre

Sendo as dezessete contribuições que contam este artigo coletivo das mais diversas, elas não deixam de sugerir o quanto é aberta, indefinida e virtualmente infinita, a questão seguinte, lema do presente trabalho: do que falamos quando falamos de música? Longe de ser um inconveniente, essa relativa indefinição do domínio da escuta musical leva ao contrário o potencial de se traduzir em pistas para futuras pesquisas; o objetivo do presente artigo não é mais nem menos que relatar quais foram as pistas exploradas pelos alunos durante o primeiro semestre de 2018, na chamada "Oficina de MP3" do nosso curso de Sociologia da música. ${ }^{1}$

\footnotetext{
${ }^{1}$ Este artigo coletivo relata a experiência de "Oficina MP3" realizada na disciplina de Sociologia da música ministrada pelo Professor Jorge de La Barre, na Universidade Federal Fluminense. A ideia era que cada aluno trouxesse e apresentasse à turma uma música da sua escolha, em toda expressividade, espontaneidade e nos seus próprios termos, sem pensar muito em tentar estabelecer alguma relação sociológica. Participaram dessa escrita coletiva experimental os alunos da turma do primeiro semestre de 2018: Gabriel Gordo Alcântara, Cid Burlamaqui de Castro Araújo, Jonathan Silva das Chagas, Marcos Roberto Ribeiro de Freitas, Victor Hugo de Arruda Aranha Barbosa, Felipe Matheus Lourenço, André de Mendonça Cerqueira Severino, Enock do Nascimento Natividade, Gabriel Ariêh Carvalho de Oliveira, Mariana Barbosa de Oliveira, Lucas Petitdemange, Marília Alves Rodrigues,
} 
De 1960 a 2018, as músicas relatadas abrangem um período de quase sessenta anos, ou três gerações. Dentre as dezessete músicas, catorze são nacionais; as outras três vêm da Polônia, do Japão e dos Estados Unidos. Não menos abrangentes, os gêneros musicais abordados vão da MPB ao rap, samba, pagode, brega, tecnobrega, punk/riot grrrl, e do black metal à música enka e soul music -confirmando ainda o carácter exploratório da pergunta inicial (do que falamos quando falamos de música?). Como não poderia deixar de ser, as temáticas abordadas nos relatos são também das mais diversas, como veremos.

Em vez de listar os temas abordados, e evitando assim de esquecer alguns, apresentamos aqui a sequência adotada, essencialmente em dois "Movimentos": uma "Abertura" sobre circulação musical, seguida pela temática música e significado ("Movimento I"). Depois de um "Interlúdio" sobre elementos biográficos, retomamos com a temática música e representação ("Movimento II"), antes de concluir numa "Coda" sobre plataformas digitais.

Circulação musical, significado musical, fronteiras simbólicas, música e representação, plataformas digitais: esses temas são de fato presentes numa sociologia contemporânea da música cuja hipótese principal seria a do carácter eminentemente social, socialmente construído das práticas, convenções e significados musicais (ver por exemplo DeNora, 2000; Hennion, 2011; Martin, 2006). Dessa forma e por assim dizer, os relatos de escuta aqui apresentados encontraram nessa sequência o seu lugar de fala coletiva.

\section{Abertura: circulação musical}

1. Kayama Yūzō, "Ki mītō itsu made ro (Sempre com você)" (1965) Marcos Roberto Ribeiro de Freitas

Com o auxílio de discussões respaldadas em outras apresentações e textos debatidos, tento aqui fazer uma análise do estilo musical enka, que talvez nos dê pistas de resposta à pergunta: do que falamos quando falamos de música?

João Vitor dos Santos, Bruna Siqueira dos Santos Señorans, Rogerio Luiz Ferreira da Silva, Camila Nazareth Souza e Silva. Editado por Jorge de La Barre (Departamento de Sociologia e Programa de Pós-Graduação em Sociologia, Universidade Federal Fluminense) e Evelyn Christine da Silva Matos (Mestre em Sociologia pelo Programa de Pós-Graduação em Sociologia, Universidade Federal Fluminense). Revisão final por Jorge de La Barre. Sobre uma outra experiência de “Oficina MP3" durante o primeiro semestre de 2017, ver La Barre et alii. (2018). 
Uma das questões que mais me chamou a atenção, certamente, foi a circulação da música. Os estilos musicais transitam em diversos espaços, se transformando à medida em que transitam. A música enka é parte constitutiva da identidade musical do Japão, mesmo sendo um estilo construído sobre referenciais musicais ocidentais, mais especificamente sob a influência da música popular tradicional dos Estados Unidos, onde uma das grandes referências seja talvez o cantor Frank Sinatra. A influência do estilo estadunidense se espalhou pelo mundo inteiro, porém não apenas "colonizando" as sonoridades locais, mas sendo incorporadas por elas, como aconteceu no Japão.

No Brasil, o estilo popular tradicional foi provavelmente difundido através da voz do cantor Júlio Iglesias e, mais localmente, por Roberto Carlos; o que indica que o distanciamento do Ocidente em relação à música enka japonesa é, sobretudo, linguística. Não se trata de considerar a questão da língua como algo menor, mas de valorizar os pontos de contato entre estilos muito populares em locais distintos que são, nesse caso, mais numerosos que os pontos de distanciamento. Considerando as diferenças regionais que o diálogo entre o global e o local produzem nessas formas musicais, Kayama Yūzō ${ }^{2}$ emociona jovens e idosos no Japão, cantando um gênero musical extremamente semelhante ao gênero musical que emocionou jovens e idosos na voz do já falecido cantor Emílio Santiago. ${ }^{3}$

\section{Movimento I: a questão do significado musical}

2. Odair José, “Uma vida só (Pare de tomar a pílula)” (1973)

Lucas Petitdemange

A proposta da Oficina de MP3 era de cada aluno escolher uma música que fosse importante para si. No meu caso, logo me passou pela cabeça que não importava qual música seria, mas ela tinha que ser do estilo que conhecemos como brega, e ainda mais, do período conhecido como "anos de chumbo". Pelo auge da repressão do governo civil-militar expressado pelo AI-5, o período ficou conhecido como o mais violento. As prisões e censuras cresceram assim como a perseguição política, atingindo todos os setores da sociedade.

\footnotetext{
${ }^{2}$ Kayama Yūzō, "Ki mītō itsu made ro": https://www.youtube.com/watch?v=4-xOORWo14s. NB: todas as músicas relatadas são acessíveis pelo YouTube; todos os links acessados em 28/08/2018.

${ }^{3}$ No seu relato em sala de aula, Marco nos explicou ter sido introduzido à música enka por um amigo nissei (segunda geração de imigrante japonês), que lhe explicava que essa era a música que seu pai costumava escutar. De fato, um belo exemplo de circulação musical, em contexto de migração!... (NdE).
} 
Sobre esse contexto, tende-se ressaltar a importância dos setores da esquerda, e colocar no hall dos heróis os autores das "músicas de protesto". A escolha de "Uma vida só (Pare de tomar a pílula)" de Odair José, ${ }^{4}$ vem como uma forma de contestar essa versão da nossa história. Uma versão que privilegia artistas como Chico Buarque e Milton Nascimento, que supostamente tiveram um papel decisivo na luta contra o regime em detrimento de artistas mais populares que tinham seu público nas camadas menos privilegiadas. Muitos desses artistas foram relegados ao ostracismo, por serem associados (erroneamente) ao governo militar.

Odair José é um desses casos. Por ser um símbolo da grande indústria fonográfica, ele foi associado ao regime militar por setores da esquerda. Contudo, ele nada tinha a ver com o regime. Muito pelo contrário, Odair foi diversas vezes censurado pelos órgãos de repressão -o que foi o caso da música escolhida. Por azar do compositor, "Uma vida só" foi censurada por ir contra um plano de higiene social por parte do regime ditatorial. $\mathrm{Na}$ época que a música de refrão "Pare de tomar a pílula" foi lançada, o governo tocava um projeto representado pela BEMFAM (a ONG "Bem Estar Familiar"), em parceria com o governo americano e que consistia em distribuir pílulas anticoncepcionais para as populações carentes do Brasil -principalmente na região Norte/Nordeste. Na época, Odair José era um dos artistas mais consumidos no Brasil, sucesso nas rádios e nas vendagens de discos. 0 impacto da música foi importante, e o governo se viu obrigado a proibir a circulação do disco após seu lançamento, recolhendo todos os discos que estavam à venda.

3. Elis Regina, “O bêbado e a equilibrista” (1979)

\section{Mariana Barbosa de Oliveira}

Escolhi essa música interpretada pela cantora Elis Regina e lançada em 1979 por dois motivos. 0 primeiro, pelo contato que eu tive com as canções produzidas pela cantora. Eu sempre tive contato com as obras e a história da cantora Elis Regina; sua forte personalidade deixou sua marca na MPB, apesar de sua morte precoce. Suas músicas são atemporais, perpetuam até os dias atuais. 0 segundo motivo se dá pelo contexto e significado da letra, escrita por Aldir Blanc e João Bosco.

"O bêbado e a equilibrista" 5 marca a anistia e a volta dos exilados da ditadura militar brasileira. Pode ser considerada símbolo, hino dos exilados.

\footnotetext{
${ }^{4}$ OdairJosé, “Umavidasó (Pare de tomar apílula)”: https://www.youtube.com/watch?v=E9uVeecg1ZI.

${ }^{5}$ Elis Regina, “O bêbado e aequilibrista”: https://www.youtube.com/watch?v=jRpEPwVxTTE.
} 
Na letra, encontramos elementos históricos que compuseram o período; a letra trata principalmente da esperança que, naquela época, parecia se perder em meio a tantas atrocidades. Portanto, escolhi essa música pelo teor histórico, por ter uma forte influência na MPB e ser considerado um clássico da música brasileira. Mas também e sobretudo, por ela (e Elis!) causar forte emoção em mim.

Pode parecer fácil se emocionar e se sentir consternado com "O bêbado e a equilibrista”. A canção pode inclusive ser considerada um estímulo para o nosso momento atual, apesar do contexto político diferente, no sentido de se manter na esperança de um futuro melhor. E o melhor é que a música não se torna démodé; ao contrário, ela se tornou um clássico que ainda interessa e emociona a muitos.

\section{Chico Buarque e Gilberto Gil, "Baticum” (1989)}

\section{Enock do Nascimento Natividade}

A música "Baticum", composta por Chico Buarque e Gilberto Gil em 1989, me foi apresentada por um amigo em 2001. Ele e eu ficamos intrigados com a letra e também gostamos da melodia. ${ }^{6} \mathrm{~A}$ música descreve uma festa, que começa com uns personagens -Bia, Clara, Dadá, Didi, Lelê- e logo é tomada por outros -Mané da Consolação, Barão do Ceará, um professor falando alemão, entre outros. Há uma mistura de agentes. No início da canção, os personagens vivem no seu mundo,

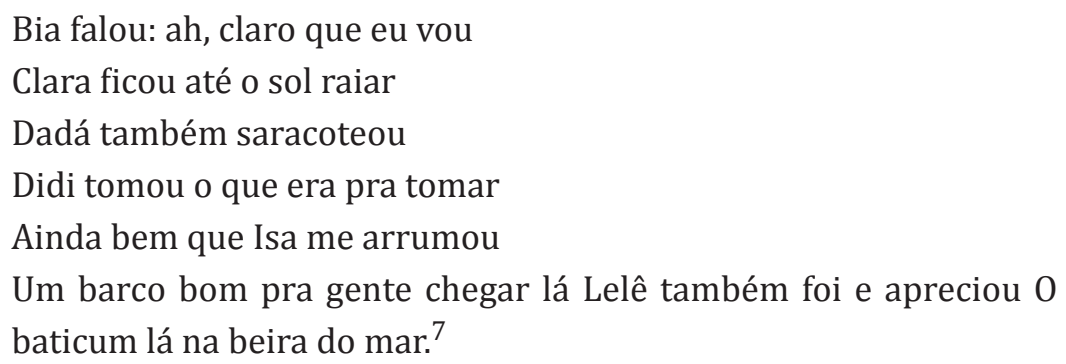

Em seguida, esse mundo parece ser rompido quando, na canção, surgem referências a pessoas possuidoras de títulos e prestígios e também a nomes de algumas empresas:

Veio Mané da Consolação

Veio o Barão de lá do Ceará

\footnotetext{
${ }^{6}$ Chico Buarque e Gilberto Gil, "Baticum”: https://www.youtube.com/watch?v=jesKWD3q0e0.

${ }^{7}$ Letras de "Baticum" (Chico Buarque): https://www.letras.mus.br/chico-buarque/85934/
} 
Um professor falando alemão

Um avião veio do Canadá

Monsieur Dupont trouxe o dossier

E a Benetton topou patrocinar A Sanyo garantiu

o som do baticum lá na beira do mar. ${ }^{8}$

Essas empresas privadas que patrocinam a tal festa parecem dar uma uniformidade, uma forma de viver ou aburguesamento. Se antes havia uma autonomia das pessoas para organizar a festa, ela passou agora a ser representada por empresas, ou seja, a liberdade não é mais do indivíduo. Não é possível afirmar se, assim como os Gregos antigos que assumiam a própria consequência da vida (tragédia), as pessoas consentiram ou não com o que ocorreu. Mas houve sim uma "publicização" da vida privada, é pelo menos o que a música tenta passar ao citar duas empresas de comunicação: "E quem não viu jamais verá / Mas se você quiser saber / A Warner gravou / E a Globo vai passar". ${ }^{9}$ Há uma mistura de cosmologia, pois as fronteiras entre o público e o privado foram rompidas.

É possível que alguém julgue essa música como não sendo uma obra de arte, se for analisá-la como uma música militante, crítica da invasão das empresas privadas nas festas e nas vidas das pessoas. Um fato histórico é que 1989 (ano do lançamento do álbum 0 eterno Deus Mu Dança no qual a canção está inserida), é o ano da derrubada do muro de Berlim; no Brasil, ocorria a primeira eleição direta para presidente, após 29 anos. No entanto, mais 29 anos depois agora em 2018, ainda não é possível conseguir interpretar a canção; há quem a julgue como obra de arte, precisamente por sua característica, ao longo dos anos, de ser de difícil interpretação. Ou seja, cada pessoa pode interpretá-la de uma maneira, e isso irá perdurar por muito tempo.

\section{Racionais MC’s, “O Homem na estrada” (1993)}

\section{Felipe Matheus Lourenço}

A música "O Homem na estrada", interpretada pelo grupo de rap Racionais MC's, foi lançada em 1993, com o álbum Raio X do Brasil. ${ }^{10}$ Uma das canções de maior sucesso do grupo, apresenta uma intensa e profunda crítica social, abordando temas como racismo, violência policial, desigualdade social, exclusão e o sistema penitenciário. “O Homem na estrada” começa

\footnotetext{
${ }^{8}$ Letras de "Baticum" (Chico Buarque): https://www.letras.mus.br/chico-buarque/85934/

${ }^{9}$ Letras de "Baticum" (Chico Buarque): https://www.letras.mus.br/chico-buarque/85934/

${ }^{10}$ Racionais MC's, “O Homem na estrada”: https://www.youtube.com/watch?v=02-h9t0VpVI
} 
com a história de um homem, ex-presidiário, afrodescendente, morador da periferia de São Paulo, em seu caminho rumo à ressocialização -o qual é a garantia oferecida pelo Estado para justificar o sistema penitenciário.

Um homem na estrada recomeça sua vida.

Sua finalidade: a sua liberdade. Que foi perdida, subtraída;

e quer provar a si mesmo que realmente mudou, que se recuperou e quer viver em paz, não olhar para trás, dizer ao crime: nunca mais! ${ }^{11}$

Entretanto, a realidade experimentada pelo personagem, reflexo de inúmeras histórias análogas na realidade brasileira, vê ocorrer justamente o inverso da proposta estatal: a discriminação e a exclusão são estigmas no qual o personagem se depara constantemente.

A Justiça Criminal é implacável.

Tiram sua liberdade, família e moral. Mesmo longe do sistema carcerário, Te chamarão para sempre de ex-presidiário. ${ }^{12}$

É justamente essa condição que trará, no final das contas, um desfecho trágico para o enredo, pois devido ao seu passado de envolvimento no mundo do crime, esse homem vai ser acusado injustamente por ter novas atividades criminosas, o que leva ao seu assassinato (ilegal e inconstitucional) pelas forças policiais na sua tentativa de trazer a "ordem".

É madrugada, parece estar tudo normal.

Mas esse homem desperta, pressentindo o mal.

Muito cachorro latindo,

Ele acorda ouvindo barulho de carro e passos no quintal. A vizinhança está calada e insegura,

Premeditando o final que já conhecem bem. Na madrugada da favela não existem leis, Talvez a lei do silêncio, a lei do cão talvez.

Vão invadir o seu barraco, é a polícia!

Vieram pra arregaçar, cheios de ódio e malícia.

Filhos da puta, comedores de carniça!

Já deram minha sentença e eu nem tava na "treta".

Não são poucos e já vieram muito loucos.

Matar na crocodilagem, não vão perder viagem. Quinze caras lá fora, diversos calibres

\footnotetext{
11 Letras de "Homem Na Estrada" (Racionais MC's): https://www.letras.mus.br/racionaismcs/79451/

12 Letras de "Homem Na Estrada" (Racionais MC's): https://www.letras.mus.br/racionaismcs/79451/
} 
E eu apenas com uma "treze tiros" automática.

Sou eu mesmo, e eu, meu Deus e o meu Orixá.

No primeiro barulho, eu vou atirar.

[...]

Homem mulato aparentando entre vinte e cinco e trinta anos é encontrado morto na estrada do

M’Boi Mirim sem número.

Tudo indica ter sido acerto de contas entre quadrilhas rivais. Segundo a polícia, a vítima tinha vasta ficha criminal. ${ }^{13}$

O papel crítico da narrativa é incontestável, se mesclando com a própria experiência subjetiva dos integrantes do grupo, como "visões de mundo" daqueles que sobrevivem em meio a condições adversas, ocasionadas pelos duros contrastes que uma sociedade baseada na lógica do capital pode oferecer. 0 caráter sociológico que podemos observar na composição é de grande interesse, justamente por apresentar a perspectiva de quem sofre o processo de violência simbólica e econômica -além de outros graves problemas sociais como o racismo. A própria trajetória dos Racionais MC's foi sempre marcada pela mobilização em prol de causas sociais, o que garantiu ao grupo um espaço de destaque na história do rap nacional, sendo sempre lembrado como "rap de mensagem", justamente em uma época (os anos 1990) onde as vertentes mais comerciais do estilo começavam a ganhar público dentro do mercado musical de massas brasileiro. Um episódio bastante curioso envolve o então Senador Eduardo Suplicy (PT-SP) que, em 2007, numa sessão da CCJ (Comissão de Constituição de Justiça) dedicada à discussão do tema da redução da maioridade penal, recitou trechos de "O Homem na estrada".

\section{Gabriel o Pensador, "Estudo errado" (1995)}

\section{Marília Alves Rodrigues}

Escolhi essa música para refletir sobre o tema da minha monografia: como os alunos que estudam em um colégio estadual escolhem sua futura profissão, como se dão esses desdobramentos? "Estudo Errado"14 foi lançado em 1995 pelo rapper Gabriel o Pensador. A música surge como uma crítica ao sistema educacional da época: o modo como os conteúdos são abordados pelos professores, a falta de consciência política, a realidade vivida dos alunos fora da sala de aula, e como isso pontua no posicionamento dentro

${ }^{13}$ Letras de "Homem Na Estrada" (Racionais MC's): https://www.letras.mus.br/racionaismcs/79451/

${ }^{14}$ Gabriel O Pensador, "Estudo errado": https://www.youtube.com/watch?v=1540Ho2qSAk\&list=R Dl540Ho2qSAk\&t=8 
da escola. A música sugere que todos esses reflexos afetam negativamente o aprendizado dos alunos: "Quase tudo que aprendi, amanhã eu já esqueci / Decorei, copiei, memorizei, mas não entendi".15

Para refletir um pouco sobre a questão das mudanças de cenário ao longo do tempo, Gabriel o Pensador em uma entrevista concedida à BBC Brasil em 2014, disse:

Os alunos precisam é entender um pouco mais sobre ética, sobre violência, sobre política, como funciona a sociedade, por que certas coisas acontecem, por que certas coisas permanecem acontecendo depois de tantos anos... (BBC Brasil, 2014).

Ou seja, apesar da música ser de 1995, Gabriel o Pensador entende que não houve muitas mudanças no cenário educacional do Brasil. Porém, dessa vez, ele atenuava suas críticas aos professores: "Para mim, o professor é o herói do dia a dia" (BBC Brasil, 2014).

\section{Behemoth, "The Satanist" (2014)}

\section{Victor Hugo de Arruda Aranha Barbosa}

A Polônia configura-se numa estrutura religiosa-social predominantemente católica, com leis bastante rígidas contra qualquer tipo de ofensas à religião. Por conta do conteúdo ocultista e anticristão da banda polonesa de black metal Behemoth, o vocalista Nergal enfrenta vários processos no tribunal polonês. As letras de Nergal chegam a flertar de modo intenso com vários elementos da cultura pagã europeia (principalmente as mitologias nórdica, eslava e grega), da filosofia de Nietzsche, da reinterpretação de elementos bíblicos da mitologia judaica -o que passa a refletir em toda a poética e estética da banda.

Lançado em 2014, o videoclipe "The Satanist"16 nos mostra uma garota andando pelas ruas agitadas, ela não consegue esconder a expressão de desolação: “Quem sou eu?”, “Não pertenço a este lugar” são perguntas, constatações que se intensificam conforme a personagem percorre a cidade em meio a cidadãos sem rosto. 0 espaço percorrido é a céu aberto, mas as sensações de claustrofobia e desespero se impõem intensamente. A garota se encontra num estado de consciência que poderíamos

\footnotetext{
${ }^{15}$ Letras de "Estudo errado" (Gabriel 0 Pensador): https://www.letras.mus.br/gabriel-pensador/66375/

${ }^{16}$ Behemoth, "The Satanist": https://www.youtube.com/watch?v=OGGwv3Zjq88
} 
classificar como anômico -trazendo o conceito de Durkheim. Ela é vigiada o tempo todo por pessoas apáticas e apesar disso ela parece invisível, tanto é grande a falta sentida da empatia. Frente ao desespero, no entanto, ela está procurando algo -mas o quê? Um jogo de xadrez se forma em sua mente, representando por assim dizer a moral cristã. Moral cristã contra o pensamento individual que busca emancipação, e um estado ascético do "pensar por si mesmo". A consciência da garota, a sua sensação de estar sendo vigiada e julgada pelos "indivíduos sem rosto" geram o conflito interno. 0 pensamento crítico é que leva a garota a tal estado "iluminado".

\section{Interlúdio: trechos biográficos}

8. Jaloo, "Chuva” (2016)

Camila Nazareth Souza e Silva

Jaloo, batizado Jaime Melo, reinventa o gênero tecnobrega brasileiro quando mescla referências artísticas nacionais e internacionais: a cantora islandesa Björk, por exemplo. ${ }^{17}$ Jaloo é do Pará, e nomeou seu estilo musical de "sci-fi brega", 18 talvez por ser nortista, nordestino, em referência à xenofobia que os nordestinos sofrem no seu cotidiano, pelo sotaque, pela cor, pela origem geográfica, por ser gay -toda uma série de fatores que o fazia ser rejeitado inclusive na região em que nasceu e cresceu. E por ser um representante de várias comunidades que sofrem de discriminação, o sucesso, a visibilidade que Jaloo conquistou é de imensurável importância.

Como sugerido no clipe "Chuva”, Jaloo apresenta uma dualidade, entre as classificações que o definem e afligem, e as que ele decidiu reivindicar logo no começo da sua carreira em 2014 ao se afirmar representante da causa $L G B T Q+$. Quatro anos depois, em 2018, Jaloo passou não só a compreender o significado de sua existência como se diz mais forte por abraçar a luta; seu papel social enquanto artista perante as lutas identitárias e de gênero torna-se uma raison d'être.

Seu aspecto feminino, seu corte de cabelo, suas roupas suscitam olhares de desconcerto nas ruas da grande São Paulo onde vive atualmente. Sua

\footnotetext{
${ }^{17}$ Jaloo, "Chuva": https://www.youtube.com/watch?v=VBcZgimFXVc

${ }^{18}$ Sci-fi: abreviação em língua inglesa do gênero literário ficção científica (science fiction). Conforme o jornalista Lucas Magno, o estilo musical de Jaloo, o "sci-fi brega”, é “uma mistura de tecnobrega com electro 8-bit e ritmos latinos, levando como principal referência do trabalho a periferia, seja ela de Belém, do Brasil ou do mundo" (Magno, 2019).
} 
aparência feminina desperta também dúvidas sobre a sua capacidade musical; entretanto Jaloo resolveu compor sua banda por mulheres. Suas composições, clipes e projetos afins apresentam todos esses aspectos da sua vida, sua feminilidade, seu julgamento político, suas afiliações -com As Bahias e a Cozinha Mineira, por exemplo, um grupo musical tão comprometido por suas pautas quanto ele.

\section{Menstruação Anarquika, "Maria Bonita” (2010) Evelyn Christine da Silva Matos}

Rebelde de minha situação social, escolhi teimar e estudar o jeito como as coisas são. Contra o fantasma da donzela em perigo, escolhi o coturno, as saídas à noite e a sagacidade de se andar na rua, de conhecer a cidade. Mas aceitando meu desajustamento social, descobri outras formas de fazer as coisas, e pretendo defendê-las... até quando eu mudar de ideia.

É prazeroso, porém desafiante, discutir essa música. ${ }^{19}$ Entre o gosto e a responsabilidade contemplativa, meus pensamentos tramitam entre as situações de contextualização por parte do meu objeto e interesse de pesquisa -o meio underground e questões relacionadas ao poder, o movimento contra-cultural e a acepção de ideologias pelas formas artísticas-, e minha experiência pessoal, que é a razão para a elucidação dessas ideias, do sentimento que se deixa tocar pela música. Faz desse discurso especialmente íntimo. Não só porque anima o exercício sociológico, mas porque faz parte da minha formação filosófica, a qual esteve alimentando minha reflexão sobre a existência, e sobre as coisas do mundo.

A banda Menstruação Anarquika, suas músicas, seu gênero -punk, riot grrrl-feito de feminismo e posicionamento político fizeram parte da definição dos meus objetivos de vida, razão de luta, e meu papel nela.

Eu poderia ter seguido outros caminhos a partir de outras reflexões poéticas e musicais, já que dos meus quinze anos em diante eu não estive ouvindo apenas punk rock. No entanto, a forma com que me falavam este e outros grupos punk provocavam idealizações que encontravam representações imediatas, práticas e concretas: a minha cidade, a minha realidade -uma coisa próxima, contextualizada. Não seriam meros devaneios poéticos e espirituais; os conteúdos ganhavam propriedade local, por meio do discurso ligeiro e coloquial. A rispidez caracteristicamente adolescente,

${ }^{19}$ Menstruação Anarquika, “Maria Bonita”: https://www.youtube.com/watch?v=q_NxD_FA2G8 
a hiper-razão, visavam uma ação direta, uma resposta imediata. Temas ecológicos e de conscientização social, a relação com os pais, com tradições familiares e religiosas, a vida, as injustiças da cidade, da escola e do trabalho, fariam tanto sentido na minha relação com os outros e com as coisas que eu me embebi desses ideais, até mesmo na eleição da carreira acadêmica.

De pequena, da educação familiar, eu já apreendia que deveria cursar a universidade; isso não se ofuscou. Eu era uma pré-adolescente estranha, encontrando na música o abraço social que me faria compreender meu lugar no mundo e refletir a razão dos meus perjúrios; eu não estaria só. Do punk rock e da minha introspecção observante, decidi que cursaria sociologia.

Neta de uma pernambucana "arretada", mais um sertanejo beberrão, rude e violento, certas histórias de meu passado familiar foram particularmente marcantes. As fábulas da minha mãe me diriam que esse meu avô teria parte com bandoleiros, com o qual aprendera a ser terrível, ainda que pouco se soubesse de fato sobre seu passado. Minha avó, por outro lado, se orgulhava de sua ascendência indígena, e em sua história estava também refletida a violência: "Minha bisavó era índia, índia mesmo; foi pega no laço ainda menina", ela diria.

Conto tudo isso para exprimir ao leitor o quão intimista é para mim a análise dessa canção, "Maria Bonita". Minha avó, hoje com 89 anos, ainda conta que se casou por afronta. Tinha dezesseis anos e queria estudar. Não poderia, porque "menina aprende a ler para escrever cartinha para namorado", dizia seu pai. Casou-se com aquele viúvo forasteiro e veio para o Rio de Janeiro, e cá estamos nós hoje.

Nossa palavra-chave talvez seja "rebeldia". 0 rebelde punk rock organiza seu movimento através do estilo -de fala, de pensamento, de expressão. A rebelde minha avó casa-se com um estranho para buscar sua liberdade, ainda que encontre muita dor. Maria Gomes de Oliveira, chamada de Maria de Déa e popularizada como Maria Bonita, rompe com a tradição colonial de "moça mansa" para viver como nômade desbravadora em uma marcha insubordinada. É a própria marcha dos Cangaceiros, que contraria a estrutura de poder que se lhe impõe, desde a sobreposição do centro, da cidade e da metrópole para com a periferia da colônia. E a marchinha carnavalesca, que oriunda a releitura feita por Menstruação Anarquika, acusa essa espinhosidade em relação à polícia, ou seja, a uma das forças autoritárias do Estado: 
Acorda, Maria Bonita

Acorda vai fazer o café 0 dia já

vem raiando E a Polícia já tá de

pé. ${ }^{20}$

Embora na versão carnavalesca, o arranjo "já tá de pé” deixe brecha para a dúvida onde, em uma flexão compreensiva, um cidadão comum poderia estar a pedir ajuda da mulher para preparar-se para o trabalho, o chamado por Maria Bonita não impede associação imediata aos bandoleiros do Cangaço. A romantização da pivô vem tratar, em todos modos, da vida de homens comuns do Sertão, sejam eles da ordem cangaceira, ou trabalhadores. Em ambas hipóteses, há o chamamento da mulher para arrumação de um movimento: fazer o café para que se aprontem; afinal, a polícia já está em atividade. Portanto, é reativo: um comportamento se dá de forma indutiva; seja em um caso ou em outro, sofre-se a pressão do Estado. Poderia ir além para evocar a força do amor ou do sentimento, da peleja de uma partida inevitável, para reforçar se tratar da vida de fora-da-lei cangaceiros, capturando a imagética do momento que Lampião justifica a agregação de sua nova esposa ao bando:

Se eu soubesse que chorando

Empato a tua viagem Meus

olhos eram dois rios Que

não lhe davam passagem.

Cabelos pretos anelados

Olhos castanhos, delicados

Quem não ama a cor morena

Morre cego e não vê nada. ${ }^{21}$

Estamos, portanto, vislumbrando parte da vida de pessoas que se não propriamente contra lei, ao menos amoral, de uma existência marginal. Refletindo a imagética de Maria Bonita, a mulher terá conquistado seu espaço e cativado sua importância em um grupo, ainda que fundado para ser alternativo, extrema e predominantemente machista. Mas não se basta aí, porque Menstruação Anarquika quer da Bonita a revolução dentro da revolução. Depois de eternizada romanticamente e de provar força e bravura pela compreensão histórica (sobre Maria Bonita, ver por exemplo Torres, 2014), a Bonita vem incitar a outras Marias Bonitas:

${ }^{20}$ Letras de "Acorda, Maria Bonita" (trad. Marchinhas de Carnaval): https://www.letras.mus.br/ marchinhas-de-carnaval/528841/

${ }^{21}$ Letras de "Acorda, Maria Bonita" (trad. Marchinhas de Carnaval): https://www.letras.mus.br/ marchinhas-de-carnaval/528841/ 
Não acorda, Maria Bonita

E nem vem fazer café

Direitos iguais pra todos E a polícia

vai se fuder! $!^{22}$

Além de outro trecho dessa nova versão, reaver a hesitação que a marchinha de carnaval precisou deixar para que passasse pelos olhares da censura e da repressão quando insubordinada, esclarece: "E a polícia já tá no pé!"23

Ambas versões -a marchinha de carnaval e a punk-abordam a vitalidade feminina em prol da organização rebelde. Ainda que outrora ganhasse espaço pela romantização e pelo cuidado, é inegável a preponderância que Maria Bonita teve enquanto esposa daquele que foi considerado Rei do Cangaço. Consentiram-lhe o porte de armas; teve conquistada certa autoridade no bando, participando de decisões -ainda que sua posição oficial fosse subalterna. É sabido da história que ela teria sido a primeira mulher a fazer parte do bando dos cangaceiros, que, inspirado no sucesso de sua adaptação, vai se tornando misto.

A versão punk agora vem exigir, usando de sua personagem, a consideração da igual potência entre os gêneros. Não só que se saiba a importância da mulher, mas que a tenha reconhecida. Explora-se a figura da Bonita para avançar nos direitos femininos, rearranjando-a na luta feminista. Atenhome à questão punk feminista, me abstendo de associar o movimento punk aos bandoleiros do Cangaço. No entanto, trato de clamar que essa comparação é, sim, possível...

\section{Movimento II: música e representação}

10. Ray Charles, “Georgia on my Mind” (1960)

André de Mendonça Cerqueira Severino

Escrita em 1930 por Hoagy Carmichael e Stuart Gorrel, a canção “Georgia on my Mind" se tornou mundialmente conhecida na interpretação do cantor Ray Charles em seu álbum The Genius Hits The Road, de 1960. ${ }^{24}$

\footnotetext{
${ }^{22}$ Letras de "Maria Bonita" (Menstruação Anarquika): https://www.letras.mus.br/menstruacaoanarquika/478139/

${ }^{23}$ Letras de "Maria Bonita" (Menstruação Anarquika): https://www.letras.mus.br/menstruacaoanarquika/478139/

${ }^{24}$ Ray Charles, "Georgia On My Mind”: https://www.youtube.com/watch?reload=9\&v=fRgWBN8y t_E.

${ }^{13}$ Gonzaguinha, "É": https://www.youtube.com/watch?v=-YmuHTOUYB4.
} 
Originalmente dirigida para uma pessoa chamada Georgia, a canção é um exemplo de como as canções ganham novas potencialidades e significações ao longo do tempo. Em 1979, “Georgia on my Mind” foi oficialmente adotada como hino do Estado da Geórgia (EUA). Em 2003, foi considerada a $44^{\underline{a}}$ maior canção de todos os tempos pela revista Rolling Stone.

Escolhi "Georgia on my Mind" inicialmente por conta do seu intérprete prodigioso, Ray Charles. 0 cantor de soul, blues e jazz tem importância fundamental na minha formação como músico; em termos de representação racial, ele aparece como um dos homens negros mais importantes da história. Então, para além da estética de "Georgia on my Mind", a sua escolha fora propositalmente política; ela se dá como um esforço contínuo surgido na comunidade negra de enaltecer na literatura, na música, na Academia e em outros campos (no sentido do conceito de Bourdieu), pessoas negras que têm produzido e cunhado um caminho para que outros artistas negros possam, igualmente, ganhar espaço na cultura pop.

11. Gonzaguinha (Luiz Gonzaga Jr.), “É” (1982)

Cid Burlamaqui de Castro Araújo

Filho do "Rei do Baião" Luiz Gonzaga, Gonzaguinha iniciou sua carreira na década de 1960, no Rio de Janeiro, convivendo com artistas como Ivan Lins e Aldir Blanc com os quais fundou o Movimento Artístico Universitário (MAU). Foi um dos compositores mais perseguidos pela ditadura militar: nos anos 1980, Gonzaguinha teve mais de 50 músicas censuradas e ganhou fama de agressivo e mal-humorado.

Composta em 1982, a música "É" 13 é considerada uma canção patriótica: ela contém o desabafo de uma juventude destruída pela ditadura militar. Seus versos clamam por condições de vida melhores, para um povo tão carente de direitos -direitos civis, direito à saúde, cidadania, solidariedade, reconhecimento e valorização de seu trabalho. É um grito contra o abuso e o desrespeito, característicos da repressão do regime ditatorial da época. "É" retrata o momento vivido no período da ditadura militar, quando a população foi amordaçada, reprimida e violentada pelo regime vigente.

Gonzaguinha usou do seu talento de compositor para dar voz a todas as necessidades e reivindicações de uma população tão oprimida. A música não deveria ser feita para divertir ou servir de pano de fundo para conversar. Para Gonzaguinha, "Música é para fazer pensar" (Malta, 2013, p. 172). 
12. Roberto Carlos \& Fundo de Quintal, "Pagode do Rei” (1986) Rogerio Luiz Ferreira da Silva

No vídeo "Pagode do Rei" 25 de 1986, podemos observar a interação entre representantes de gêneros musicais distintos: Roberto Carlos, e o grupo Fundo de Quintal. Roberto Carlos, cantor e compositor que desponta com o pop-rock da "Jovem Guarda" com suas baladas românticas, considerado o "Rei" pelo sucesso de suas músicas que perdura até hoje, e os sambistas do Fundo de Quintal que, no momento, estavam em alta: Jovelina Pérola Negra, Almir Guineto, Zeca Pagodinho.

O vídeo é do programa de TV especial de final de ano do Roberto Carlos, regularmente veiculado pela Rede Globo de Televisão a cada 25 de dezembro. Nesse ano de 1986, o termo "pagode" já tem conotação de estilo, ou subgênero, dentro do gênero musical samba. Os artistas que estão juntos ao "Rei" são de uma geração que modificou consideravelmente a maneira de se apresentar o samba, introduzindo instrumentos novos, lançando cantores, cantoras e instrumentistas que entram para a história do gênero. Segundo Nei Lopes (2003) no seu livro Sambeabá, essa mudança foi por assim dizer a última "revolução do samba"!

No vídeo, vemos um pequeno acompanhante do Rei Roberto Carlos: o garoto é Anderson Leonardo, que dez anos mais tarde protagonizaria uma geração de sambistas menos ligada às "traições do gênero", ${ }^{26}$ e que alcançaria um sucesso estrondoso pelo Brasil. Temos, então, uma interação entre diferentes gerações e gêneros musicais, entre pop-rock, samba, pagode. Importante é lembrar que essa intermediação se dá num programa anual de final do ano, reunindo artistas populares, o que se traduz em audiência, fazendo ao mesmo tempo uma experimentação sonora quando Roberto Carlos se põe a versar de improviso.

A própria música "Pagode do Rei” trata-se de um "Partido alto", modalidade do samba que pressupõe um refrão fixo intercalado por versos improvisados. Os sambistas ali presentes são representantes legítimos dessa maneira de se fazer samba de improviso; já Roberto Carlos não é sambista, mas ele demonstra, na ocasião, que ele também sabe "improvisar".

\footnotetext{
25 Roberto Carlos \& Fundo de Quintal, "Pagode do Rei”: https://www.youtube.com/ watch?v=xJVBdDKwzfQ

${ }^{26} \mathrm{O}$ trocadilho com "tradições" faz referência à produção de Roberto Carlos. Tal como comenta Oliveira (2012), "encontrar qualidades na produção de RC ou em outras qualificadas como românticas, ou "'bregas", é por vezes sentido como uma espécie de traição, ou desqualificado enquanto gesto provocativo inconsequente" (p. 154).
} 
13. Itamar Assumpção, “Cultura Lira Paulistana” (1998)

Gabriel Ariêh Carvalho de Oliveira

Francisco José Itamar de Assumpção foi um importante cantor e compositor que obteve destaque nas décadas de 1980 e 90 na cena alternativa paulistana. Foi um dos expoentes do movimento cultural conhecido como "vanguarda paulista", movimento que tinha como prioridade encorajar a iniciativa independente e o rompimento com as grandes gravadoras -estas que acabavam por controlar a produção e o lançamento de novos artistas no meio musical. Assim como muitos artistas pertencentes à vanguarda paulista, Itamar Assumpção gerenciava a gravação e produção dos seus próprios discos.

Os "críticos especializados", embotados pela burocracia das gravadoras, encaravam a obra de Itamar Assumpção como confusa e de difícil acesso, fator que contribuiu para que ele e outros artistas, tanto da vanguarda paulista quanto de outros movimentos como, por exemplo, o tropicalista Jards Macalé, fossem categorizados como "malditos da MPB". Os malditos eram artistas que, apesar do notório talento musical e reconhecimento, não possuíam o apelo comercial característico dos sons difundidos pelas gravadoras -o que limitava o acesso do público aos seus materiais.

Uma das grandes preocupações de Itamar Assumpção era com o que estava sendo veiculado no Brasil como "cultura", principalmente no âmbito musical. A música "Cultura Lira Paulistana”, ${ }^{27}$ presente no álbum Pretobrás de 1998, aborda o tema de forma incisiva, começando com o trecho...

Pobre cultura

A ditadura pulou fora da política

E como a dita cuja "é craca é crica" Foi grudar bem na cultura Nova forma de censura. ${ }^{28}$

[...] onde quem detém o controle dos meios de informação -televisão, rádio etc.- decide também do que é difundido ou não como "cultura". Itamar critica a superficialidade das músicas consideradas populares na época, e chama a atenção para problemáticas que eram até então vistas como uma característica recorrente em várias músicas presentes nos meios de divulgação em massa, como por exemplo, a vulgarização da mulher. Durante a música, Itamar Assumpção cita diversos artistas que eram antes

\footnotetext{
${ }^{27}$ Itamar Assumpção, “CulturaLira Paulistana”: https://www.youtube.com/watch?v=PHLmdaNGcVM

${ }^{28}$ Letras de "Cultura Lira Paulistana" (Itamar Assumpção): https://www.letras.mus.br/itamar-assumpcao/272421/
} 
valorizados como expoentes da cultura brasileira, e acabaram sendo jogados em segundo plano por não atenderem à demanda do novo meio comercial. É interessante observar que muitos dos "malditos" são hoje em dia considerados "cult", valorizados inclusive pelos meios de divulgação em massa que optavam por ignorá-los antes. Temos como exemplo a música "Feito gente", composta por Walter Franco em 1975 e usada na novela da Globo, de 2017, Os Dias Eram Assim.

Itamar Assumpção faleceu em 2003, deixando nove discos em vida e três discos póstumos. Conhecido por ter sido uma figura polêmica, uma de suas frases mais emblemáticas acabou por ser uma premonição do que estava por vir na sua carreira musical: "Eu só vou fazer sucesso depois de morto".

\section{O Rappa, "Auto-Reverse" (2013)}

\section{Jonathan Silva das Chagas}

Escolhi a música "Auto-Reverse", do álbum "Nunca tem fim" de O Rappa, ${ }^{29}$ lançado em 2013, por me identificar com a banda e perceber em sua arte elementos do cotidiano da cultura periférica, sobretudo do Rio de Janeiro. A banda possui um ritmo diversificado, sem se prender a um único estilo musical -o que poderia até mesmo ser considerado um estilo próprio e original. Com letras bastante abstratas e filosóficas, suas canções costumam utilizar uma linguagem popular, apreendendo gírias e expressões derivadas das periferias do Estado do Rio, como a Baixada Fluminense e a Zona Oeste.

O Rappa aborda temas comuns e populares, mas sempre de uma forma abrangente, que permita uma reflexão ampla e uma interpretação diversa, onde cada um possa encontrar um sentido próprio para as letras. Como a banda aborda problemas sociais cotidianos das periferias, o público dessas regiões acaba se identificando. Isso não ocorre somente pela letra das músicas, como também pela sonoridade, o ritmo e a melodia, assim como pela atitude da banda, que, apesar de já ter alcançado um patamar de sucesso nacional, se apresenta de maneira bastante informal.

0 nome da banda remete à atividade em que os camelôs no Rio de Janeiro alertam uns aos outros sobre a presença da Guarda municipal que vem para cumprir a ordem de apreensão de mercadoria dos vendedores ambulantes irregulares emitida pela Prefeitura e pelo Governo do Estado, que, muitas vezes se traduz também pela detenção dos mesmos. Tendo isto

${ }^{29}$ O Rappa, "Auto-Reverse": https://www.youtube.com/watch?v=vgZwa7GKRCA 
como contexto, "Auto-Reverse" fala sobre união, sobre pessoas que apesar de todas as dificuldades arrumam uma forma de superar, de "dar a volta por cima" como se costuma dizer, e de continuar sua batalha sempre celebrando bons momentos juntos. 0 clipe conta histórias de superação a partir de personagens singulares, como: um ex-presidiário, um rapaz com deficiência motora campeão da Batalha do passinho e, em especial, o afilhado do vocalista Falcão, que tem Síndrome de Down.

O Rappa se tornou uma das maiores referências no cenário musical do Rio de Janeiro, levando seu estilo por onde passa para atingir o âmbito nacional. Considero a banda uma das poucas que consegue me agradar por sua musicalidade variada; em certa medida, poderíamos até mesmo compará-la a um Red Hot Chili Peppers nacional, que atrai um público de múltiplos e díspares gostos musicais, além da boa avaliação popular de seu trabalho, onde está sempre inovando e se renovando.

15. Well \& Djonga, "Muito bem feito" (2017)

\section{João Vitor dos Santos}

Como o próprio nome da música diz, os rappers Djonga e Well fazem um trabalho "muito bem feito", 30 isto é, complexo e elaborado em diversos aspectos. Acredito que o que melhor demonstra isso é a quantidade -e qualidade- das referências que eles evocam em sua música. Claramente, a música é pautada na questão da representatividade e do empoderamento negro e rapper.

Primeiramente, o vídeo (de 2017) é gravado em Pampulha, ponto emblemático da cidade de Belo Horizonte. É possível entender que ambos os artistas têm como objetivo usar esse espaço para se mostrarem importantes na cena do rap brasileiro. Djonga diz na música: "Somos negros com atitude, BH virou Compton" -em referência aos rappers de NWA (Niggaz Wit Attitude), originários da cidade de Compton na Califórnia: Ice Cube, Dr. Dre (assim como, mais recentemente, o rapper Kendrick Lamar). Outro aspecto da música que cabe ressaltar é o número de referências a outros artistas, principalmente negros. Por parte de Djonga, são citados dezenove artistas (incluindo ele mesmo), sendo dez deles negros. Na voz de Djonga, temos:
Assisti Fruitvale Station
Chorei pacarai,
É um filme que o preto morre no final, Tá rindo, né pai?

\footnotetext{
${ }^{30}$ Well \& Djonga, "Muito bem feito": https://www.youtube.com/watch?v=0nsg9FwBRo4
} 
Frantz Fanon que o diga, Tira essa máscara branca ${ }^{31}$

Em outro momento,

Os pretos são presentes Christmas Merry

Me chame Marighella, sem Fleury pra matar Sou

lampião, mesmo escuro, luz no sertão Tente me apagar. ${ }^{32}$

E em referência a acontecimentos que massacraram uma população majoritariamente negra, "No país do Carandiru ou da Candelária / MC's disputando quem come mais cu / Que coisa hilária". ${ }^{33}$ Well, por sua vez, caracteriza o empoderamento negro ao comparar dois atletas, e se colocar também na posição de ativista: "Avisa pros Stephen Curry (ha) / Que nois joga tipo King James". ${ }^{34}$ Em outro momento o artista diz: "São pretos no comando de novo / Me sinto um headhunter / Representando meu povo / Instinto Black Panther". ${ }^{35}$

Diante desses aspectos, "Muito bem feito" tem por objetivo demonstrar o orgulho, a importância e a influência negra, de forma não só a citar nomes, mas, como artistas que conhecem a massa, mostrar e representar esses artistas por meio de sua própria arte, essencializando o lema Ubuntu: “Eu sou porque nós somos". Dito por Djonga: "Os menor leu bell hook / E foi minha a ideia, irmão / Enquanto cês num fizer isso / Lembra Tropa de Elite? / Jamais serão". 36

\section{Coda: plataformas digitais}

16. 3030, "Mundo de ilusões" (2012)

\section{Gabriel Gordo Alcântara}

A música "Mundo de ilusões", 37 da banda de rap acústico carioca 3030, foi escolhida porque seu conteúdo, em questão de letra e ritmo, teve forte impacto na minha vivência enquanto ouvinte. A música aborda uma

\footnotetext{
${ }^{31}$ Letras de "Muito bem feito" (Well): https://www.letras.mus.br/well/muito-bem-feito/

${ }^{32}$ Letras de "Muito bem feito" (Well): https://www.letras.mus.br/well/muito-bem-feito/

${ }^{33}$ Letras de "Muito bem feito" (Well): https://www.letras.mus.br/well/muito-bem-feito/

${ }^{34}$ Letras de "Muito bem feito" (Well): https://www.letras.mus.br/well/muito-bem-feito/

${ }^{35}$ Letras de "Muito bem feito" (Well): https://www.letras.mus.br/well/muito-bem-feito/

${ }^{36}$ Letras de "Muito bem feito" (Well): https://www.letras.mus.br/well/muito-bem-feito/

${ }^{37}$ 3030, "Mundo de ilusões": https://www.youtube.com/watch?v=9qhUNdcFugM
} 
questão existencial, fazendo referência a um lugar na Bahia que seria dos mais calmos:

Meu bem, o que eu queria era estar na Bahia Com você, não existe um final.

Sem luz, sem energia, sem carro, sem correria Colhendo frutas no meu quintal. ${ }^{38}$

Fuga ao cotidiano nas grandes cidades, a música traz diversas críticas à sociedade contemporânea; algumas questões como a desigualdade e alienação são abordadas em versos que falam de uma "multidão surda e muda, sem visão", de pessoas que "fingem não prestar atenção quanto estão amordaçados pela manipulação". 0 combate à manipulação se daria com a construção de uma outra realidade, impulsionada pela dor de viver numa sociedade violenta, transformando o sofrimento em poesia.

Nesse instante, pessoas brilhantes crescem nas favelas.

Em um instante ideias brilhantes morrem atrás de telas

Nas novelas em um anúncio de TV

Monitores que amenizam dores, falsos amenizadores (...). ${ }^{39}$

Outro aspecto da questão é que escolhi essa música em sala de aula a partir da rede 4G do meu smartphone, quando o prédio estava sem acesso à Internet. A minha apresentação foi assim marcada por discussões acerca do papel da tecnologia na disseminação e no consumo de mídias musicais. A questão posta, a discussão foi sobre portais digitais tais como Spotify e YouTube, que facilitam o acesso a conteúdo alinhado ao que você costuma ouvir, selecionando e até pré-determinando aquilo que você deve consumir. Por um lado, esses portais proporcionam facilidade de acesso a diversas músicas; por outro, eles são também capazes de produzir "bolhas digitais" para que você consuma só aquilo que supostamente lhe agrada. Nesse universo pré-programado, há grandes chances de que ele lhe restrinja de conhecer coisas novas.

Refletimos sobre as novas maneiras de se ouvir música. Em contraponto à época dos vinis e CDs, quando se parava para apreciar a música, o que se observa hoje em dia é um escutar mais "corrido", estimulado pelos smartphones e aplicativos que facilitam o acesso no trabalho, no carro, na

\footnotetext{
${ }^{38}$ Letras de "Mundo de ilusões" (3030): https://www.letras.mus.br/3030/mundo-de-ilusoes/

${ }^{39}$ Letras de "Mundo de ilusões" (3030): https://www.letras.mus.br/3030/mundo-de-ilusoes/
} 
rua -demonstrando do resto, a importância da música na vida cotidiana, nas suas mais diversas dimensões.

17. MC Loma e as Gêmeas Lacração, "Envolvimento” (2018) Bruna Siqueira dos Santos Señorans

Ao apresentar as duas versões do videoclipe "Envolvimento", de MC Loma e as Gêmeas Lacração, pretendo fazer um contraponto entre a produção independente e a passagem para o mainstream através das novas plataformas digitais de música. A Internet adensa-se como plataforma de difusão musical, onde artistas independentes colocam suas caseiras criações, susceptíveis de ser "captadas" por produtoras estabelecidas.

Colocado no ar em 20 de janeiro de 2018, o primeiro videoclipe "Envolvimento" conta hoje com 47.042.484 visualizações. ${ }^{40} 0$ boca a boca entre YouTubers e digital influencers, além do agrado público, levaram as meninas da periferia do Recife a um novo patamar no cenário musical recifense, e logo brasileiro. Colocado no ar em 09 de fevereiro apenas uns quinze dias depois do primeiro, o segundo clipe é produzido profissionalmente pela KondZilla, que detém seu próprio canal no YouTube. 0 hit "viralizou", alcançando hoje umas 218.956 .955 visualizações, ou seja, quase cinco vezes mais do que a versão caseira (trata-se da mesma música original, só o visual do clipe é novo). ${ }^{41}$

Com um ritmo popular e uma letra deliberadamente "chiclete" ("Esse hit é chiclete, na sua mente vai ficar", diz a letra), MC Loma e as Gêmeas Lacração encontram abertura para outros trabalhos com produtoras além da própria KondZilla, e com grandes nomes do funk no cenário musical atual, como por exemplo MC Kelvinho, autor do hit "Fuleragem" (a parceria "Paralisia”).

\section{Para não concluir..}

Jorge de La Barre

Talvez o leitor encontre, nesse caleidoscópio em dezessete ângulos que ele acabou de explorar, alguns elementos de resposta -fragmentários, por definição- à pergunta acordada (Do que falamos quando falamos de

${ }^{40}$ MC Loma e as Gêmeas Lacração, “Envolvimento” (versão “caseira” inicial): https://www.youtube. com/watch?v=pOpyq-T4fnQ.

${ }^{41}$ MC Loma e as Gêmeas Lacração, “Envolvimento" (versão produzida pela KondZilla): https://www. youtube.com/watch?v=lgJOJAmXlBw. 
música?). Desde há pelo menos uma geração (metade dos anos 1990), as tecnologias digitais ampliaram, multiplicaram de forma vertiginosa uma circulação musical observada há tempo, nomeadamente em situações de migração ("Abertura"). Na era das tecnologias digitais, os "produtos derivados" da circulação musical têm nomes estabelecidos, naturalizados. Além do empréstimo ou da apropriação, contamos com os samples, remixes, mashups...

Sendo o significado musical socialmente construído (literalmente, investimos a música com significados), ele não deixa de funcionar como operador de diferenciação social. Como vimos, a oposição entre mainstream e underground (ou, mais específica ao Brasil, entre MPB e brega ou tecnobrega) é um marcador da existência de fronteiras simbólicas que sempre se deslocam e assim permanecem -lembrando também a distinção entre centro e periferia, ainda relevante (sobre essa questão, ver por exemplo La Barre, 2012).

Lembrar que nós depositamos na música quantidade de significados socialmente construídos é lembrar também o poder de representação da música -dimensão que o sociólogo da Escola de Frankfurt Theodor Adorno não deixava de questionar, inclusive esteticamente, em relação ao mercado de massa. Mais do que julgar a música (genial ou brega?), ou decretar seu poder de representação singular única (por exemplo: rap: música da periferia; black metal: música do demônio), o sociólogo contemporâneo entende a importância de escutar os outros (inclusive os outros sociólogos!), ${ }^{42}$ a fim de tentar perceber o quanto a música, sempre debatida e reinterpretada, chega a representar as pautas do seu tempo.

Apenas nos relatos aqui apresentados, a música denunciou, criticou, acusou ("Movimento I"): o racismo, a segregação, injustiça, o sistema de educação, a ditadura, os anos de chumbo, a moral cristã... Ela falou, cantou, gritou ("Interlúdio"): outros gêneros, e outras coisas e outras pessoas também. Ela representou, sempre no singular ("Movimento II"): uma cidade, um Estado, um país, um povo, uma cor, uma raça... Essa capacidade de falar em nome do(s) outro(s), essa alteridade, não seria o próprio da representação, sua singularidade?

Last but not least ("Coda"), lembremos que todos os relatos foram apresentados a partir de uma plataforma digital única: o canal de vídeos YouTube.

${ }^{42}$ Ver, por exemplo, a palestra de Les Back, proferida no Programa de Pós-Graduação em Sociologia da Universidade Federal Fluminense em 17 ago. 2018: "What Sociologists Learn from Music". 
A nossa experiência musical contemporânea é de fato cada vez mais mediada pelos canais, plataformas, telas e telinhas. Melhor dizendo, a experiência musical contemporânea é de uma permanente imersão tecno-sensorial. No entanto, por ser tão óbvio, o óbvio dessa nossa condição de imersão é às vezes esquecido, naturalizado. Mas enfim, naturalizado não seria sinônimo de socialmente construído? 


\section{Bibliografia}

" BBC Brasil (2014). Gabriel Pensador: 'Professor é herói do dia a dia'. G1, 29 ago. 2014. Recuperado de http://g1.globo.com/educacao/noticia/2014/08/ gabriel-pensador-professor-e-heroi-do-dia-a-dia.html

»DeNora, T. (2000). Music in Everyday Life. Cambridge \& New York: Cambridge University Press.

»Hennion, A. (2011). Pragmática do gosto. Desigualdade \& Diversidade Revista de Ciências Sociais da PUC-Rio, 8, 253-277.

» La Barre, J. de (2012). Para além da oposição centro/periferia: das fronteiras simbólicas à economia simbólica. In S.M. Fernández, P. Roxo e I. Iglesias (Eds.). Músicas e saberes em trânsito. Lisboa: Edições Colibri / Instituto de Etnomusicologia - Centro de Estudos em Música e Dança / SIBE - Sociedad de Etnomusicologia (publicação eletrônica).

» La Barre, J. de, Andrade, S., Burry, C., Cortes, C.E. e Lima, O.O. (Eds.) (2018). Para falar em (sociologia da) música. Relatos de (uma Oficina de) escuta. Revista Ensaios, 12, 119-138.

»Lopes, N. (2003). Sambeabá: O samba que não se aprende na escola. Rio de Janeiro: Casa da Palavra.

» Magno, L. (2019). Conheça Jaloo, cantor e produtor musical paraense que faz show em Fortaleza neste sábado (5). Márcia Travessoni. Recuperado de https://marciatravessoni.com.br/entretenimento/conheca-jaloo-cantor-eprodutor-musical-paraense-que-faz-show-em-fortaleza-neste-sabado-5/

» Malta, D. (2013). Obrigado, Flávio Cavalcanti - Luiz Gonzaga Jr. In C. Albuquerque (Org.). 1973. O ano que reinventou a MPB. A história por trás dos discos que transformaram a nossa cultura (pp. 170-174). Rio de Janeiro: Sonora.

»Martin, P. J. (2006). Music and the Sociological Gaze. Art Worlds and Cultural Production. Manchester \& New York: Manchester University Press.

» Oliveira, A. (2012). Roberto Carlos e a identidade brasileira na canção. Revista do Instituto de Estudos Brasileiros, 54, 151-166.

" Torres, F. (2014). A verdade por trás de Maria Bonita. Obvious. Recuperado de http://lounge.obviousmag.org/sarcasmo_e_sonho/2014/08/a-verdadepor-tras-de-maria-bonita.html 


\section{Biografias / Biografías /Biographies}

Jorge de La Barre é Professor Adjunto do Departamento de Sociologia e Metodologia das Ciências Sociais (GSO-UFF), Professor Permanente do Programa de Pós-Graduação em Sociologia da Universidade Federal Fluminense (PPGS-UFF), e Professor Colaborador do Programa de Pós-Graduação em Música da Universidade Federal de Pernambuco (PPGM-UFPE).

Evelyn Christine da Silva Matos é Mestre em Sociologia pela Universidade Federal Fluminense; tem uma especialização em Educação das Relações Étnico-raciais na Educação Básica pelo Colégio Pedro II (interrompida em 2019); e é especializada em Gestão e Administração Escolar pela Faculdade Única de Ipatinga.

Gabriel Gordo Alcântara é graduando em Sociologia pela Universidade Federal Fluminense.

Cid Burlamaqui de Castro Araújo é graduando em Sociologia pela Universidade Federal Fluminense.

Jonathan Silva das Chagas é graduando em Sociologia pela Universidade Federal Fluminense.

Marcos Roberto Ribeiro de Freitas é Mestrando em Sociologia pelo Programa de Pós-graduação em Sociologia (UFF). Possui Licenciatura em Ciências Sociais pela Universidade Federal Fluminense (UFF) (2019), e graduação em Ciências Contábeis pela Universidade Estácio de Sá (2010).

Victor Hugo de Arruda Aranha Barbosa é graduando em Sociologia pela Universidade Federal Fluminense.

Felipe Matheus Lourenço é graduando em Sociologia pela Universidade Federal Fluminense.

André de Mendonça Cerqueira Severino é pós-graduando em Sociologia Política pelo Instituto Universitário de Pesquisas do Rio de Janeiro. Possui graduação em Sociologia pela Universidade Federal Fluminense (2019); é editor do Blog Discursos Pedestres. 
Enock do Nascimento Natividade possui Licenciatura em Ciências Sociais pela Universidade Federal Fluminense (2019); graduação em Administração pela Universidade Federal Rural do Rio de Janeiro (2004).

Gabriel Ariêh Carvalho de Oliveira é graduando em Sociologia pela Universidade Federal Fluminense.

Mariana Barbosa de Oliveira é graduanda em Ciências Sociais pela Universidade Federal Fluminense.

Lucas Petitdemange é graduando em Ciências Sociais pela Universidade Federal Fluminense.

Marília Alves Rodrigues é graduanda em Sociologia pela Universidade Federal Fluminense; cursa especialização em Saúde Mental e Atenção Psicossocial na Universidade Estácio de Sá; possui graduação em Psicologia pela Universidade Salgado de Oliveira.

João Vitor dos Santos é graduando em Sociologia pela Universidade Federal Fluminense.

Bruna Siqueira dos Santos Señorans é graduanda em Ciências Sociais pela Universidade Federal Fluminense.

Rogerio Luiz Ferreira da Silva é graduando em Ciências Sociais pela Universidade Federal Fluminense.

Camila Nazareth Souza e Silva é graduanda em Ciências Sociais pela Universidade Federal Fluminense. 